\title{
Critical appraisal of amlodipine and olmesartan medoxomil fixed-dose combination in achieving blood pressure goals
}

This article was published in the following Dove Press journal: Integrated Blood Pressure Control 18 June 2010

Number of times this article has been viewed

\section{Jan Basile}

Professor of Medicine, Medical University of South Carolina, Charleston, SC, USA
Correspondence: Jan Basile Medical University of South Carolina, 109 Bee Street, Charleston, SC 29403, USA

$\mathrm{Tel}+\mathrm{I} 84357750 \mathrm{II}$ ext 6680

Fax + I 8438055798

Email basilejn@musc.edu

\begin{abstract}
Hypertension remains a significant health burden in the United States, with almost one in three adults affected, and is an independent risk factor for cardiovascular and renal disease. The goal of antihypertensive treatment is to reduce cardiovascular and renal morbidity and mortality by reducing blood pressure (BP). Guidelines recommend a target BP of $<140 / 90 \mathrm{mmHg}$, with a more stringent goal of $<130 / 80 \mathrm{mmHg}$ for patients with diabetes and chronic renal disease. However, BP goal attainment rates remain low and most patients require therapy with two or more antihypertensive agents. Combination antihypertensive therapy usually employs agents from different classes, thus benefitting from complementary mechanisms of action to achieve greater BP control with fewer side effects. Patient adherence to therapy is enhanced by formulating treatments as fixed-dose (single-pill) combinations. One example is the combination of amlodipine, a dihydropyridine calcium channel blocker (CCB), with olmesartan medoxomil, an angiotensin receptor blocker (ARB). Here, the rationale for the use of CCB/ARB combination therapy is discussed, as well as the pharmacology and tolerability of the amlodipine/olmesartan medoxomil combination and its efficacy in terms of achieving BP goal in patients with hypertension. Advantages of its use from the patient's perspective are also discussed.
\end{abstract}

Keywords: amlodipine, angiotensin receptor blockers, calcium channel blockers, fixed-dose combination therapy, hypertension, olmesartan medoxomil

\section{Introduction}

Hypertension affects nearly 1 in 3 adults in the United States, ${ }^{1-3}$ and is an important modifiable risk factor for coronary artery disease, heart failure, renal failure, and stroke. ${ }^{4,5}$ An analysis of global data suggests that the overall prevalence of hypertension is similar in men and women and increases with age. ${ }^{6}$ According to a recent estimate, hypertension was responsible for around 7.6 million premature deaths per year, contributing $6.0 \%$ to the total global disease burden. ${ }^{7}$

Hypertension control correlates with a significant reduction in cardiovascular (CV) events. $^{2}$ Indeed, over the last 50 years, reductions observed in CV event-related morbidity and mortality have been attributed to the increased availability and use of antihypertensive treatments. ${ }^{2}$ In particular, blood pressure (BP) reductions in patients with diabetes mellitus are linked with reductions in disease events. ${ }^{8}$ However, the United States National Health and Nutrition Examination Survey (NHANES) findings for 2003 to 2004 showed that adequate BP control was achieved in only $37 \%$ of patients with hypertension and in only $57 \%$ of those who received antihypertensive therapy. ${ }^{1}$ Furthermore, because hypertension can be asymptomatic, many patients go undiagnosed and thus it remains a major public health challenge in the United States. ${ }^{1}$ submit your manuscript | www.dovepress.com

Dovepress

9691 
American guidelines for the management of hypertension recommend that all individuals should achieve a BP target of at least $<140 / 90 \mathrm{mmHg}$, with a target of $<130 / 80 \mathrm{mmHg}$ for patients with diabetes or chronic renal disease., ${ }^{4,9}$ Recently revised guidelines from the European Society of Hypertension (ESH) recommend lowering $\mathrm{BP}$ to values within the range of $130-139 / 80-85 \mathrm{mmHg}$ in all patients with hypertension. ${ }^{10}$ However, despite agreement over the benefits of hypertension control, there is no consensus as to the optimal choice of antihypertensive agents. ${ }^{4}$ Additionally, recent guidelines recommend different antihypertensive protocols depending on the underlying morbidities and patient characteristics. ${ }^{4}$ For example, in patients with stable angina, a beta $(\beta)$-blocker and an angiotensin-converting enzyme (ACE) inhibitor or an angiotensin receptor blocker (ARB) are recommended, whereas in patients with severe left ventricular (LV) dysfunction, the addition of an aldosterone antagonist and a thiazide or loop diuretic are recommended. In Black patients with severe LV dysfunction, the combination of hydralazine/isosorbide dinitrate is recommended as an adjunct to diuretic, $\mathrm{ACE}$ inhibitor or $\mathrm{ARB}$, and $\beta$-blocker regimens. ${ }^{4}$ In all cases of hypertension, lifestyle modifications including weight loss, diet changes, exercise, smoking cessation, and alcohol moderation are recommended. ${ }^{4,11}$

\section{Concept of combination therapy to attain BP goals}

Hypertension treatment guidelines emphasize the importance of starting treatment with combination therapy, especially in patients whose BP exceeds the goal by more than 20/10 mmHg. ${ }^{9}$ Guidelines recommend combining different classes of antihypertensive agents that have complementary mechanisms of action, an antihypertensive effect that is greater than that of either component alone, and a favorable tolerability profile. ${ }^{8}$ Furthermore, patient adherence appears to be greater with single-pill combination treatment because of greater efficacy and a reduced pill burden. ${ }^{10,12}$

Recently published results from a randomized, double-blind study showed effective BP lowering with combination therapy. ${ }^{13}$ Each of the three dual-therapy combinations produced significant $(P<0.0001$ vs baseline) reductions from baseline in both mean seated systolic BP (SeSBP) and diastolic BP (SeDBP) in patients with moderate or severe hypertension $(\mathrm{N}=2,271)$. The therapies were all possible dual combinations of a dihydropyridine calcium channel blocker (DHP-CCB; amlodipine), a thiazide diuretic (hydrochlorothiazide [HCTZ]), and an ARB (valsartan). The DHP-CCB/ $\mathrm{ARB}$ combination produced numerically greater $\mathrm{BP}$ reductions than the other combinations. ${ }^{13} \mathrm{~A}$ triple combination of these agents enabled even greater reductions than the dual therapies and has been approved by the United States Food and Drug Administration (FDA).

\section{Current antihypertensive drug options}

Several effective classes of antihypertensive drugs are currently available, including ACE inhibitors, ARBs, a direct renin inhibitor, $\beta$-blockers, $\mathrm{CCBs}$, and thiazide-type diuretics. Two-drug combinations found to be effective and well tolerated include: ACE inhibitor/thiazide diuretic, ARB/thiazide diuretic, DHP-CCB/ACE inhibitor, DHP-CCB/ARB, DHP$\mathrm{CCB} /$ thiazide diuretic, DHP-CCB/ $\beta$-blocker, direct renin inhibitor/HCTZ, ${ }^{8}$ and a very recently FDA-approved direct renin inhibitor/ARB combination. ${ }^{14}$ Figure 1 shows possible combinations of some of these classes of agents; preferred combinations recommended by treatment guidelines are indicated with a thick line.

\section{The rationale for fixed-dose (single-pill) combinations of DHP-CCBs and ARBs}

Single-pill DHP-CCB/ARB combinations are emerging as convenient and rational options for antihypertensive treatment. ${ }^{15}$ As previously demonstrated, combination antihypertensive therapy provides greater BP-lowering effects than single-agent therapy, and the added benefit of a DHP-CCB/ARB combination is a reduction in the incidence of adverse events. ${ }^{15}$ For example, when an ARB and DHP-CCB are administered together, the complementary BP-reducing mechanism of action of an ARB appears to offset DHP-CCB-induced edema. ${ }^{15}$

Furthermore, ARBs can be used at increasingly higher doses without compromising tolerability, ${ }^{16}$ have organ-protective effects, ${ }^{17}$ and are associated with a lower risk of cough and angioedema compared with ACE inhibitors. ${ }^{18}$ In addition to a mechanism of action complementary to ARBs, CCBs also provide $\mathrm{CV}$ benefits. ${ }^{19} \mathrm{An}$ amlodipine-based treatment regimen prevented more $\mathrm{CV}$ events in the BP-lowering arm of the Anglo-Scandinavian Cardiac Outcomes Trial (ASCOT) compared with atenolol-based therapy. ${ }^{20}$ In patients with coronary artery disease and diastolic $\mathrm{BP}(\mathrm{DBP})<100 \mathrm{mmHg}$, treatment with amlodipine reduced the incidence of $\mathrm{CV}$ events compared with placebo in the CAMELOT (Comparison of Amlodipine vs Enalapril to Limit Occurrences of Thrombosis) study. ${ }^{21}$ Administration of CCBs has been shown to be associated with stroke prevention relative to other antihypertensive agents, as well as a reduction in all-cause mortality. ${ }^{19}$ 


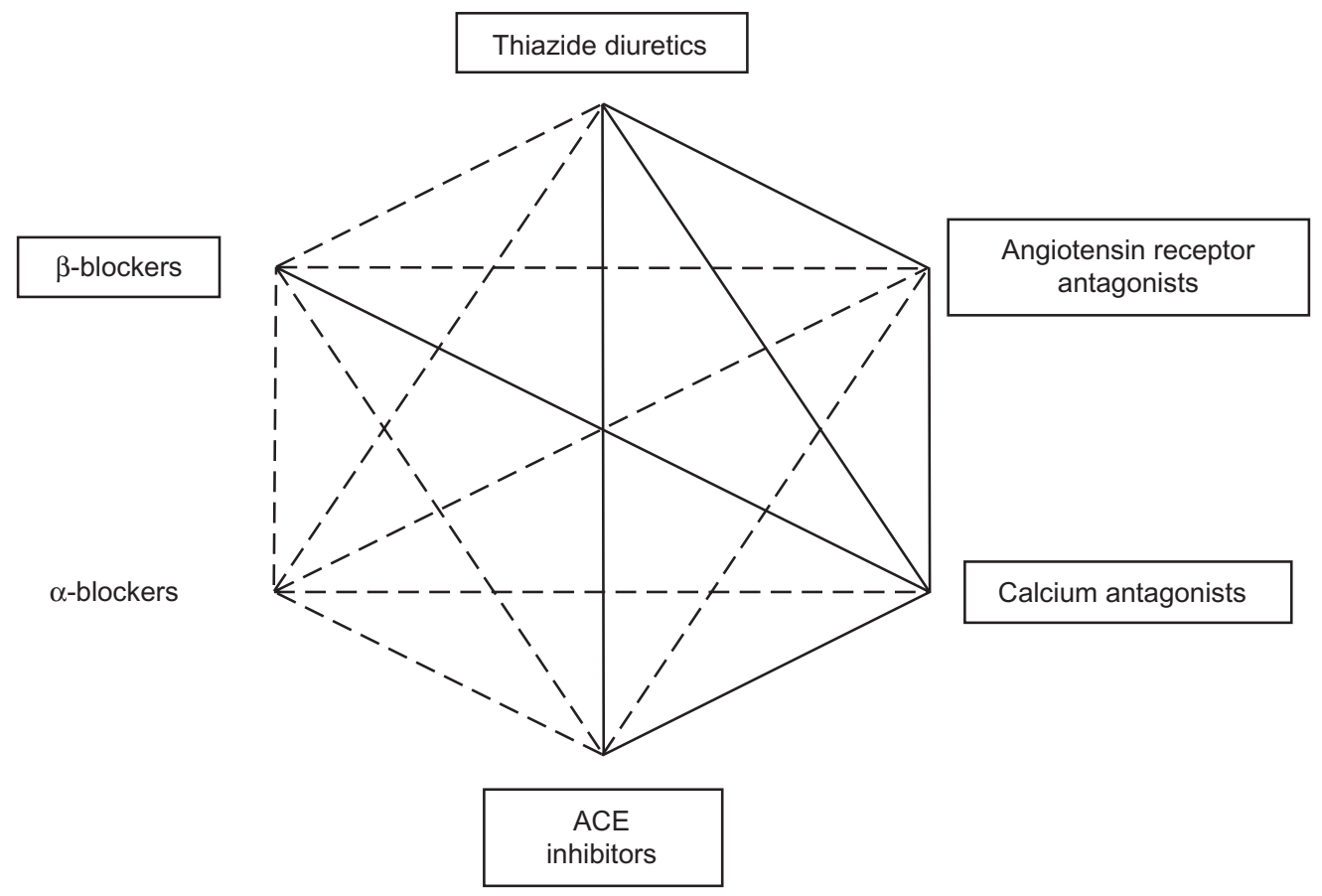

Figure I Possible combinations between some classes of antihypertensive agents. Framed agents have shown clinical benefit in interventional trials. Reproduced with permission from Mancia G, De Backer G, Dominiczak A, et al. 2007 guidelines for the management of arterial hypertension: the task force for the management of arterial hypertension of the European Society of Hypertension (ESH) and of the European Society of Cardiology (ESC). J Hypertens. 2007;25(6):II05-II87. Copyright (C) 2007 Lippincott, Williams \& Wilkins.

Abbreviation: ACE, angiotensin-converting enzyme.

In the ACCOMPLISH (Avoiding Cardiovascular Events Through Combination Therapy in Patients Living with Systolic Hypertension) trial, a DHP-CCB/ACE inhibitor (benazepril) combination provided a greater reduction in $\mathrm{CV}$ events in patients with hypertension at high risk for such events than was provided with a diuretic (HCTZ)/ ACE inhibitor combination. ${ }^{22} \mathrm{BP}$ control $(<140 / 90 \mathrm{mmHg})$ was achieved by $74.5 \%$ and $72.4 \%$ of patients in the DHP$\mathrm{CCB} / \mathrm{ACE}$ inhibitor and diuretic/ACE inhibitor groups, respectively. It is possible to speculate that by extrapolating these data to DHP-CCB/ARB combinations similar benefits may be observed because both ACE inhibitors and ARBs act on the renin-angiotensin-aldosterone system (RAAS).

Results from the large ONTARGET (Ongoing Telmisartan Alone and in Combination with Ramipril Global Endpoint Trial) study in patients with vascular disease or high-risk diabetes showed that treatment with an ARB (telmisartan) was associated with a reduction in death from CV causes, myocardial infarction or stroke, or hospitalization for heart failure (primary endpoint) that was equivalent to the risk reduction observed with an ACE inhibitor. ${ }^{18}$ Of note, the rates of angioedema $(P<0.01)$ and cough $(P<0.001)$ were significantly lower in the ARB group than in the ACE inhibitor group. ${ }^{18}$ In the LIFE (Losartan Intervention For Endpoint reduction in hypertension) study, losartan prevented more death and CV morbidity than atenolol and was better tolerated. ${ }^{23}$

In the United States, a fixed-dose combination of amlodipine and olmesartan medoxomil (AZOR ${ }^{\circledR}$; Daiichi Sankyo, Inc.; Parsippany, NJ; 5/20, 5/40, 10/20, and 10/40 mg) is indicated for first-line treatment in patients unlikely to reach their BP goal with monotherapy. ${ }^{24}$ This article will review the mechanism of action, pharmacology, and pharmacokinetics of amlodipine/ olmesartan medoxomil, and evaluate the efficacy of this combination for achieving BP goals in patients with hypertension. The tolerability of the combination will also be discussed, along with advantages of its use from the patient's perspective.

\section{Amlodipine/olmesartan medoxomil: pharmacokinetics and mechanism of action Amlodipine pharmacokinetics}

Following oral administration of therapeutic dosages, amlodipine is slowly absorbed from the gastrointestinal (GI) tract, and the time to peak plasma concentrations is 10 to 14 hours. ${ }^{25}$ Steady-state concentrations are reached after 7 to 8 days. Amlodipine does not undergo significant first-pass metabolism, but is slowly metabolized to inactive metabolites 
in the liver. ${ }^{26}$ Primarily excreted in the urine, amlodipine has an elimination half-life of 35 to 45 hours. ${ }^{25}$

\section{Olmesartan medoxomil}

\section{pharmacokinetics}

Olmesartan medoxomil is a prodrug that undergoes ester hydrolysis in the GI tract to form its active metabolite (olmesartan), which, once absorbed, does not undergo further metabolism and is excreted in the urine. ${ }^{27}$ After rapid absorption from the GI tract, peak plasma concentrations are achieved in 1 to 2 hours, followed by an elimination half-life of 13 hours. ${ }^{24}$ Steady-state concentrations are reached within 3 to 5 days, and accumulation in the plasma does not occur with once-daily dosing. ${ }^{24}$

\section{Pharmacokinetics of amlodipine and olmesartan medoxomil administered}

\section{as a combination}

No significant pharmacokinetic drug-drug interactions occur when olmesartan medoxomil and amlodipine are co-administered in separate dosage forms. ${ }^{28,29}$ When orally administered as a fixed-dose combination, amlodipine/olmesartan medoxomil is bioequivalent to single-entity dosage forms of both drugs. ${ }^{28}$

Bioequivalence was demonstrated during single- and multi-dose phase I trials in healthy volunteers who received concomitant amlodipine and olmesartan medoxomil in separate dose forms and together in a fixed-dose amlodipine/olmesartan medoxomil $10 / 40 \mathrm{mg}$ tablet formulation (Figure 2) ${ }^{28}$ For example, following a single dose of the combination tablet, peak plasma concentrations of amlodipine and olmesartan were 7.6 and $833.3 \mathrm{ng} / \mathrm{mL}$, and values for the area under the plasma concentration-time curve were 424.8 and $5,374.2 \mathrm{ng} \cdot \mathrm{h} / \mathrm{mL}$, respectively. ${ }^{28}$ Corresponding values following administration of amlodipine $10 \mathrm{mg}$ and olmesartan medoxomil $40 \mathrm{mg}$ as two separate dosage forms were 7.4 and $810.3 \mathrm{ng} / \mathrm{mL}$ and 410.9 and 5,418.6 $\mathrm{ng} \cdot \mathrm{h} / \mathrm{mL}$, respectively. ${ }^{28}$

Other pharmacokinetic parameters remain similar when amlodipine and olmesartan medoxomil are administered in either a fixed-dose combination or as individual components. For instance, peak plasma concentrations in the fixed-dose combination were achieved in about 8 hours for amlodipine and 2 hours for olmesartan, and terminal elimination halflives in the fixed-dose combination were about 40 to 55 hours for amlodipine and 11 to 16 hours for olmesartan. ${ }^{28}$

\section{Mechanism of action}

\section{ARBs}

Angiotensin receptor blockers act by selectively binding to the $\mathrm{AT}_{1}$ receptor, blocking the effects of angiotensin II, and therefore suppressing vasoconstriction and other adverse $\mathrm{CV}$ effects of angiotensin II. ${ }^{30-32}$ Angiotensin II is the predominant effector peptide of the RAAS, which plays a key role in fluid and electrolyte balance and ultimately, BP regulation. ${ }^{30}$

Compared with most other ARBs, olmesartan medoxomil exhibits a high degree of selectivity for the $\mathrm{AT}_{1}$ receptor, to which it binds with high affinity. In vitro findings showed that olmesartan was second only to telmisartan in binding affinity for the $\mathrm{AT}_{1}$ receptor; the other comparators were candesartan, valsartan, and losartan. ${ }^{33}$ Like other ARBs, olmesartan medoxomil has a low affinity for the $\mathrm{AT}_{2}$ receptor, which is also activated by angiotensin II, but is believed to have a vasodilatory effect and a protective role in $\mathrm{BP}$ regulation and sodium excretion (Figure 3). ${ }^{34}$

\section{CCBs}

Calcium channel blockers decrease the entry of calcium ions into cells by blocking L-type calcium channels, leading to relaxation of arterial smooth muscle, peripheral vasodilation, and lowered BP. ${ }^{35}$ Peripheral vasodilation is achieved through greater effects on calcium channels in arteries and arterioles than on cardiac muscle cells; CCBs do not affect serum calcium levels (Figure 3).

\section{Efficacy of amlodipine and olmesartan medoxomil combination therapy COACH study}

The efficacy of an amlodipine + olmesartan medoxomil free combination was assessed in patients $(\mathrm{N}=1,940)$ with mild-to-severe hypertension in the $\mathrm{COACH}$ (Combination of Olmesartan Medoxomil and Amlodipine Besylate in Controlling High Blood Pressure) study, which was a randomized, double-blind, placebo-controlled study conducted over eight weeks. ${ }^{36}$ Patients were aged $\geq 18$ years with an SeDBP of 95 to $120 \mathrm{mmHg}$. The 12 treatment groups were: amlodipine 5 or $10 \mathrm{mg}$ monotherapy, olmesartan medoxomil 10,20 , or $40 \mathrm{mg}$ monotherapy, each possible amlodipine + olmesartan medoxomil combination, and placebo.

The primary endpoint was the change from baseline in mean SeDBP at the end of the 8-week double-blind treatment period using the last observation carried forward (LOCF) method. Secondary variables included the proportions of patients achieving prespecified JNC 7 (Seventh Report of the Joint National Committee on Prevention, Detection, Evaluation, and Treatment of High Blood Pressure) ${ }^{9}$ recommended BP goals. The safety analysis also included an active assessment 

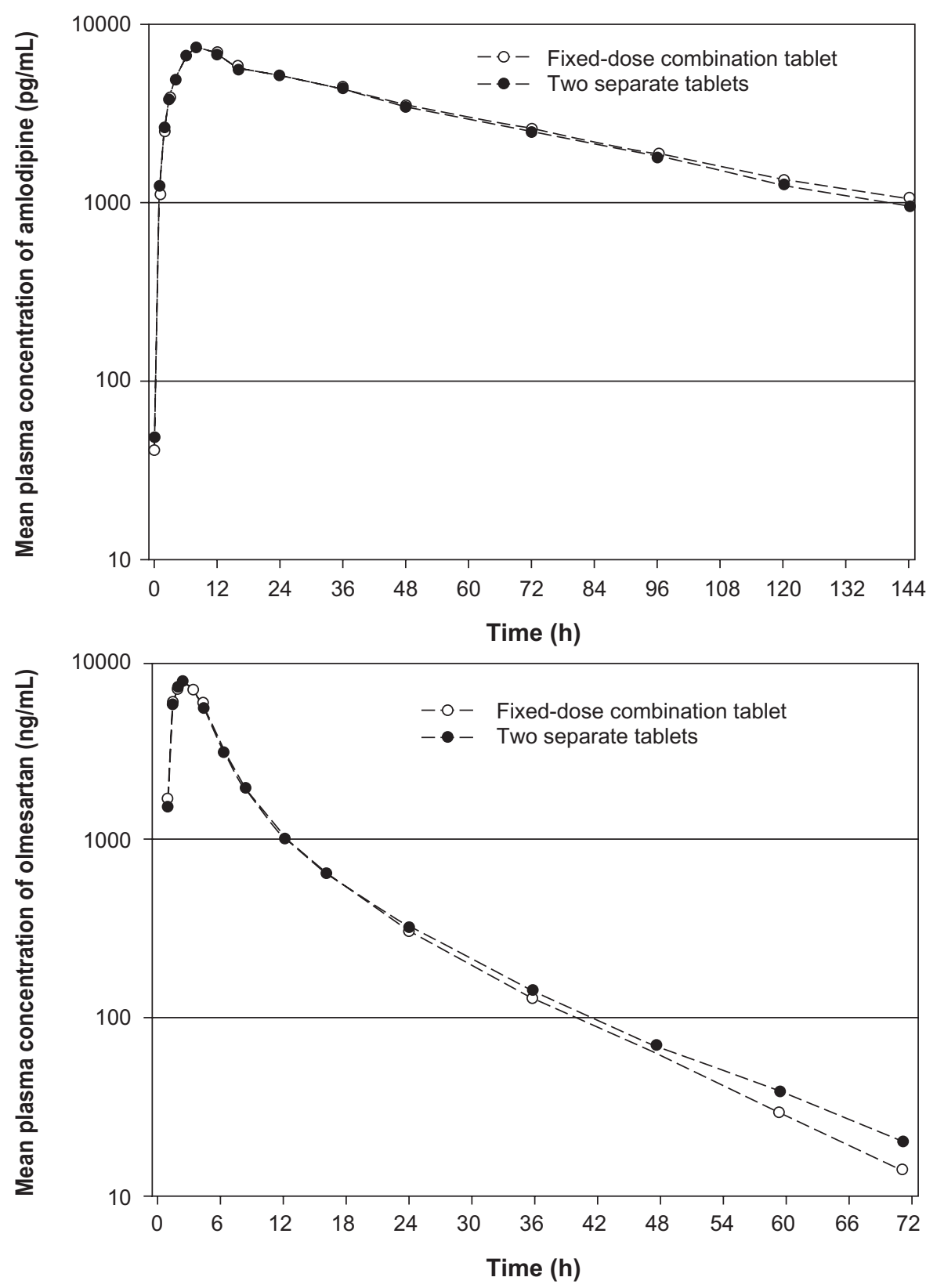

Figure 2 Mean plasma concentration profiles of amlodipine (upper panel) and olmesartan (lower panel) after administration of single-pill amlodipine/olmesartan medoxomil 10/40 mg combination therapy and concomitant administration of the two drugs and single tablets. Reproduced with permission from Rohatagi S, Lee J, Shenouda M, et al. Pharmacokinetics of amlodipine and olmesartan after administration of amlodipine besylate and olmesartan medoxomil in separate dosage forms and as a fixed-dose combination. J Clin Pharmacol. 2008;48(I I):1309-1322. Copyright @ 2008 Sage Publications.

of edema, with specific ratings for the incidence and severity of peripheral edema at scheduled visits. Edema was recorded as an adverse event when its severity increased following randomization.

The mean seated BP (SeBP) of the 1,940 patients who were randomized was $164 / 102 \mathrm{mmHg}$, and $79.3 \%$ had Stage 2 hypertension. The majority of patients were white (71.4\%), $19.8 \%$ were aged $\geq 65$ years, and $54.3 \%$ were male. In the study cohort, there were $13.5 \%$ of patients with diabetes and $64.6 \%$ with a body mass index $(\mathrm{BMI}) \geq 30 \mathrm{~kg} / \mathrm{m}^{2}$.
At 8 weeks, significant reductions from baseline in SeDBP (primary endpoint) were observed in all active treatment groups and in those receiving placebo $(P<0.001$ for all groups). Reductions from baseline in SeSBP were also significant in all active treatment groups $(P<0.001)$ and in placebo recipients $(P<0.05)$. Of note, SeDBP reductions with combination treatment were significantly greater than those observed with equivalent doses of monotherapy with either amlodipine or olmesartan medoxomil (Figure 4). Mean changes from baseline in mean SeDBP with amlodipine + olmesartan medoxomil ranged 


\section{ARB MOA}
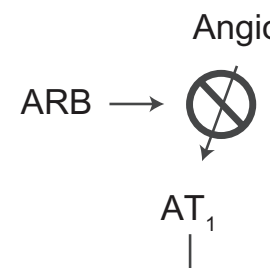

$\downarrow$ Vasoconstriction

Aldosterone secretion

$\downarrow$ Catecholamine release

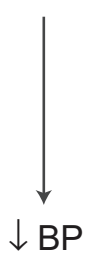

\section{CCB MOA}

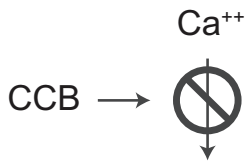

L-type $\mathrm{Ca}^{++}$Channel
$\downarrow$

$\uparrow$ Arterial vasodilation

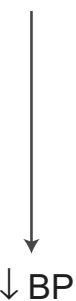

Figure 3 Complementary mechanisms by which ARBs and CCBs lower BP. ARBs block the effects of angiotensin II at the AT, receptor thus suppressing vasoconstriction. $\mathrm{CCBs}$ block the entry of calcium into cells allowing arterial smooth muscle to relax causing peripheral vasodilation. These complementary activities cause reductions in blood pressure. Reproduced with permission from Neutel JM. Complementary mechanisms of angiotensin receptor blockers and calcium channel blockers in managing hypertension. Postgrad Med. 2009;121(2):40-48. Copyright @ 2009 JTE Multimedia, LLC.

Abbreviations: ARB, angiotension receptor blocker; CCB, calcium channel blocker; MOA, mechanism of action.

from -14.0 to $-19.0 \mathrm{mmHg}$ with $5+20 \mathrm{mg}$ and $10+40 \mathrm{mg}$, respectively, whereas changes with monotherapy dosages of amlodipine were $-9.4 \mathrm{mmHg}(5 \mathrm{mg})$ and $-12.7 \mathrm{mmHg}(10 \mathrm{mg})$, and with olmesartan medoxomil were $-8.3 \mathrm{mmHg}(10 \mathrm{mg})$,
$-9.2 \mathrm{mmHg}(20 \mathrm{mg})$, and $-10.2 \mathrm{mmHg}(40 \mathrm{mg})(P<0.001$ for all comparisons vs combination treatment).

Similarly, dose-dependent reductions in SeSBP were greater with combination amlodipine + olmesartan medoxomil

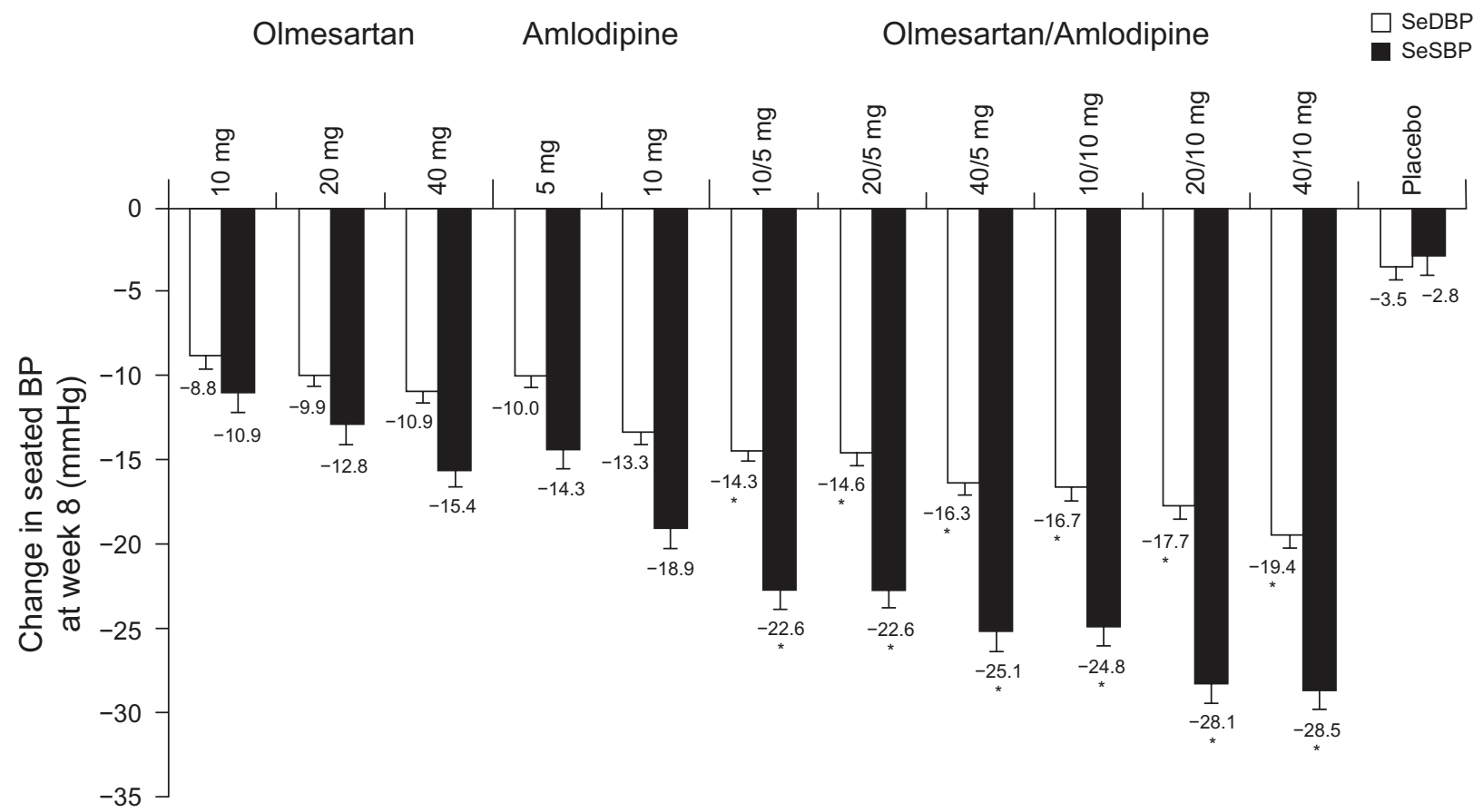

Figure 4 Least-squares mean (standard error) reduction in seated blood pressure (BP) after 8 weeks of treatment with placebo, amlodipine and olmesartan medoxomil monotherapy, and amlodipine + olmesartan medoxomil combination therapy in the COACH study. Amlodipine/olmesartan medoxomil is available as $5 / 20,5 / 40$, $10 / 20$, and 10/40 mg fixed-dose combinations in the United States. Reproduced with permission from Chrysant S, Melino M, Karki S, Lee J, Heyrman R. The combination of olmesartan medoxomil and amlodipine besylate in controlling high blood pressure: $\mathrm{COACH}$, a randomized, double-blind, placebo-controlled, 8-week factorial efficacy and safety study. Clin Ther. 2008;30(4):587-604. Copyright (C) 2008 Elsevier.

Abbreviations: SeDBP, seated diastolic BP; SeSBP, seated systolic BP. 
therapy than with equivalent dosages of the individual monotherapies (Figure 4) and were significant for all active treatment groups $(P<0.001)$ and placebo $(P=0.024)$.

An antihypertensive effect was evident within the first 2 weeks of active treatment, during which time the greatest mean SeBP reduction occurred. Reductions in BP plateaued at Week 4 and were maintained until study end without further notable reductions.

The prespecified BP goal of $<140 / 90 \mathrm{mmHg}$ $(<130 / 80 \mathrm{mmHg}$ for patients with diabetes) was attained by a significantly greater proportion of combination therapy recipients than by monotherapy recipients. After 8 weeks of treatment, the proportion of amlodipine + olmesartan medoxomil recipients achieving their BP goal ranged from $35.0 \%$ to $53.2 \%$, compared with $20.0 \%, 26.4 \%$, and $36.3 \%$ receiving olmesartan medoxomil 10, 20, or $40 \mathrm{mg} /$ day, and $21.1 \%$ and $32.5 \%$ receiving amlodipine 5 or $10 \mathrm{mg} /$ day $(P<0.005$ combination vs monotherapies) (Figure 5).

\section{Prespecified subanalyses of the $\mathrm{COACH}$ patient cohort}

Prespecified subgroup analyses showed that the amlodipine + olmesartan medoxomil combination produced significant reductions from baseline in mean SeDBP and SeSBP, irrespective of the severity of hypertension (Stage 1 or 2 ) or prior antihypertensive treatment. ${ }^{37}$

Most amlodipine + olmesartan medoxomil combinations were associated with significantly greater SeBP reductions than component monotherapies in patients with Stage 1 hypertension and all in Stage 2 patients. ${ }^{37}$ Furthermore,

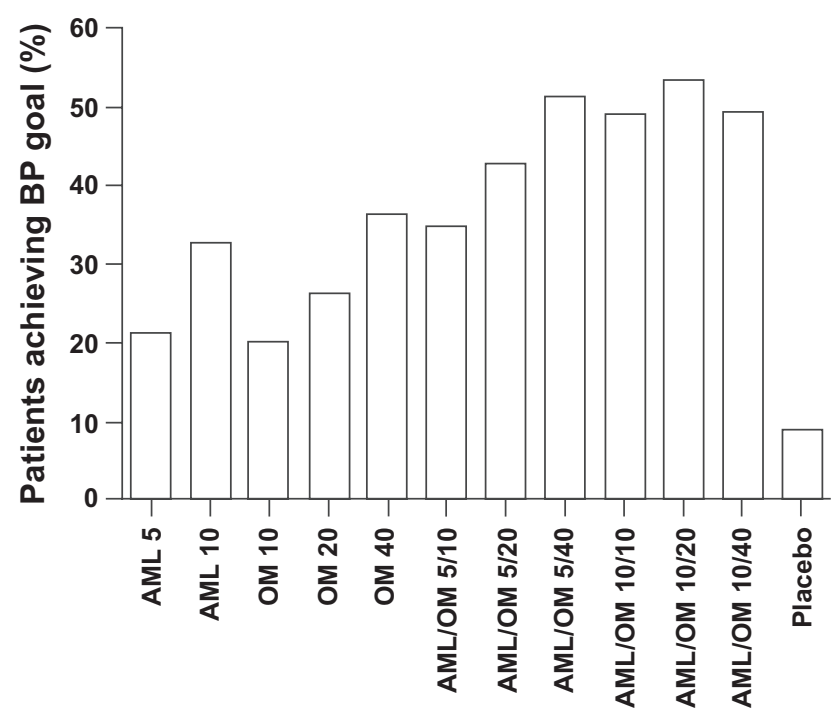

Figure 5 Percentage of patients achieving BP goal in the COACH study. (Adapted with permission from Table III in Chrysant et al). ${ }^{36}$

Abbreviations: AML, amlodipine; OM, olmesartan medoxomil. of patients with Stage 1 hypertension, $65.6 \%$ to $80.0 \%$ who received amlodipine + olmesartan medoxomil combination therapy achieved the prespecified BP goal, compared with $40.5 \%$ to $66.7 \%$ of monotherapy component recipients ( $P<0.0001$ across treatment groups) (Figure 6). Among those with Stage 2 hypertension, combination therapy that included amlodipine $10 \mathrm{mg}$ resulted in $40.5 \%$ to $49.2 \%$ of patients achieving BP goal, compared with $13.1 \%$ to $29.2 \%$ of monotherapy component recipients (Figure 6) ${ }^{37}$ In a post hoc analysis of patients with baseline SeSBP $\geq 180 \mathrm{mmHg}$, combination amlodipine + olmesartan medoxomil therapy produced even greater SeSBP reductions from baseline of 43.5 and $40.8 \mathrm{mmHg}$ for the $10+20$ and $10+40 \mathrm{mg}$ dosages, respectively. ${ }^{37}$

Among antihypertensive treatment-naive and non-naive patients, all combination therapy dosages resulted in significantly greater SeBP reductions compared with monotherapy. ${ }^{37}$ Proportionally, more patients (both treatment naive [36.2\%-55.0\%] and non-naive [31.3\%-52.9\%]) who received combination therapy achieved prespecified BP goals than their counterparts who received monotherapies $(21.8 \%-37.7 \%$ and $18.0 \%-35.5 \%$, respectively; $P<0.0001$ across all treatment groups for combination vs monotherapy). ${ }^{37}$

Prespecified subgroup analyses of the $\mathrm{COACH}$ study based on age ( $\geq 65$ or $<65$ years), race (Black or non-Black), or absence of diabetes, and BMI ( $\geq 30$ or $<30 \mathrm{~kg} / \mathrm{m}^{2}$ ) showed that combination therapy enabled greater SeBP reductions than monotherapy. ${ }^{38}$ Changes from baseline in mean SeBP for amlodipine + olmesartan medoxomil $10+40 \mathrm{mg}$ were $-33.9 /-20.9 \mathrm{mmHg}$ in patients aged $\geq 65$ years, $-28.7 /-15.7 \mathrm{mmHg}$ for Blacks, $-30.3 /-18.4 \mathrm{mmHg}$ in patients with diabetes, and $-29.7 /-17.9 \mathrm{mmHg}$ in patients with a BMI $\geq 30 \mathrm{~kg} / \mathrm{m}^{2}$. Combination therapy generally allowed more patients to achieve BP goal than monotherapy. The rate of BP goal achievement was lower in patients with diabetes due to the aggressive target of $<130 / 80 \mathrm{mmHg}$. ${ }^{38}$

\section{Amlodipine/olmesartan medoxomil following amlodipine or olmesartan medoxomil monotherapy}

The efficacy of amlodipine/olmesartan medoxomil combination therapy has also been assessed in clinical studies where patients initially received amlodipine ${ }^{39}$ or olmesartan medoxomil $^{40}$ monotherapy (Table 1). The efficacy of amlodipine/ olmesartan medoxomil following amlodipine monotherapy was assessed in a randomized, double-blind, parallel-group, multicenter study ${ }^{39}$ The study comprised of 24 weeks of 


\section{A. HTN stage}

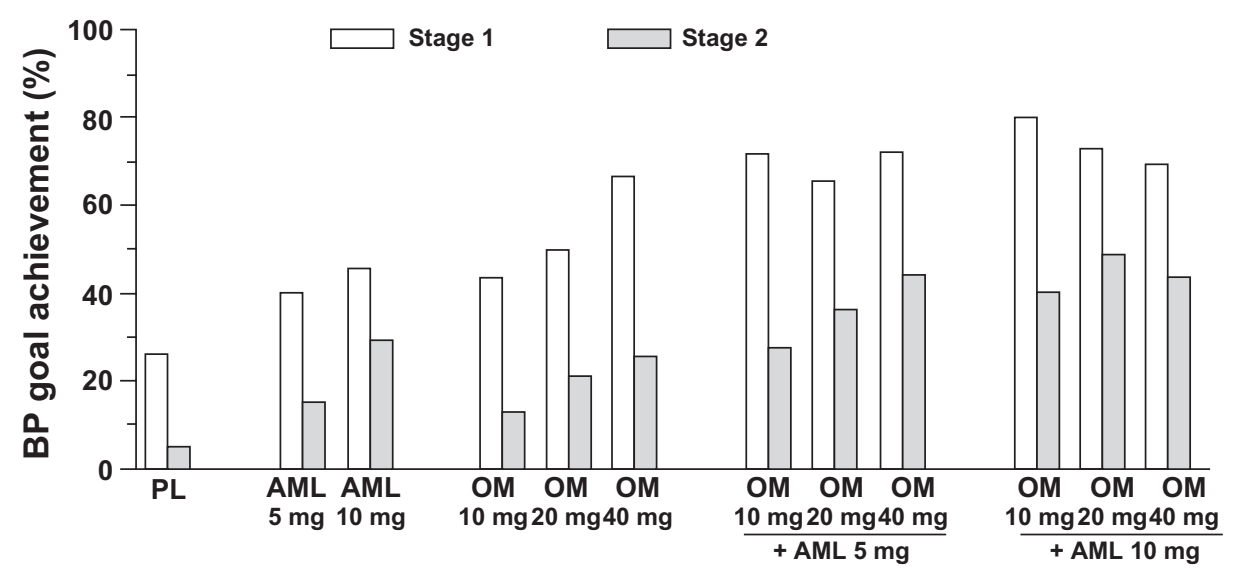

\section{B. Antihypertensive agent status}

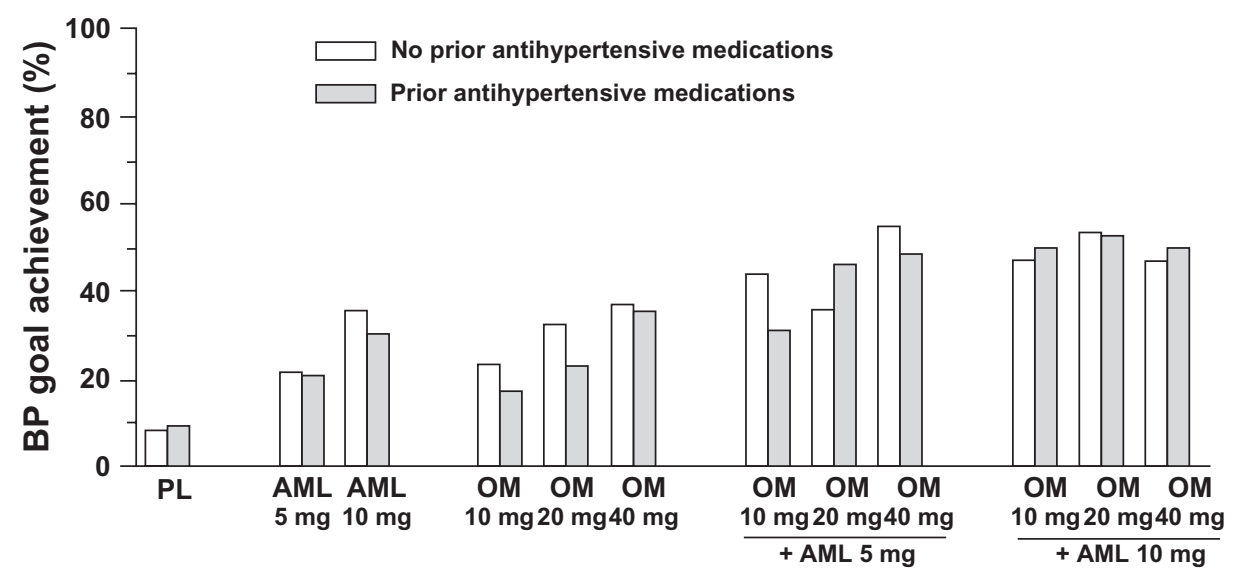

Figure 6 Achievement of BP goal in patients with Stage I and 2 hypertension (upper panel) and based on prior antihypertensive exposure (lower panel) in the COACH study. Reproduced with permission from Oparil S, Lee J, Karki S, Melino M. Subgroup analyses of an efficacy and safety study of concomitant administration of amlodipine besylate and olmesartan medoxomil: evaluation by baseline hypertension stage and prior antihypertensive medication use. J Cardiovasc Pharmacol. 2009;54:427-436. Copyright () 2009 Lippincott, Williams \& Wilkins.

Abbreviations: AML, amlodipine; HTN, hypertension; OM, olmesartan medoxomil.

active treatment. In Period I (Weeks 0 to 8) patients received open-label amlodipine $5 \mathrm{mg}$. At the end of the open-label period, non-responders, with mean $\mathrm{SeDBP} \geq 90 \mathrm{mmHg}$, mean $\mathrm{SeSBP} \geq 140 \mathrm{mmHg}$, and mean 24-hour DBP $\geq 80 \mathrm{mmHg}$ (with $\geq 30 \%$ daytime DBP $>85 \mathrm{mmHg}$ ), entered Period II, where patients were randomized to 1 of 4 double-blind treatment groups: amlodipine $5 \mathrm{mg}$ plus placebo or a combination of amlodipine/olmesartan medoxomil 5/10, 5/20, or 5/40 mg for 8 weeks. At the end of Period II, patients with SeDBP $<90 \mathrm{mmHg}$ or SeSBP $<140 \mathrm{mmHg}$ remained on their current therapy for a further 8 weeks (Period III). For patients with SeDBP $\geq 90 \mathrm{mmHg}$ and SeSBP $\geq 140 \mathrm{mmHg}$, study medication was further up-titrated (Table 1).

The primary efficacy endpoint was change in mean SeDBP from the end of Period I (after the amlodipine run-in) to the end of Period II and the secondary endpoint was change in mean SeSBP values for the same period. All SeBP changes for combination therapy were significant compared with amlodipine monotherapy $(P<0.05$ vs amlodipine/olmesartan medoxomil 5/10 mg; $P<0.0001$ vs amlodipine/ olmesartan medoxomil 5/20 and 5/40 mg). ${ }^{39}$

Up-titration of medication for patients not at the SeBP goal at the end of Period II for a further 8 weeks of therapy enabled additional SeBP reductions and allowed more patients to achieve their BP goal (Table 1). Overall, at the end of the 24 -week duration of the study, $63 \%$ of patients achieved a SeBP threshold of $<140 / 90 \mathrm{mmHg}$. ${ }^{39}$

In a similar study, the efficacy of amlodipine/olmesartan medoxomil following olmesartan medoxomil monotherapy was examined. ${ }^{40}$ The primary efficacy endpoint was the change in mean SeDBP from the end of the olmesartan medoxomil monotherapy period to the end 
Table I Randomized double-blind, parallel-group, multicenter studies assessing efficacy of AML/OM following AML or OM monotherapy

\begin{tabular}{|c|c|c|c|c|c|c|}
\hline Study & \multicolumn{3}{|l|}{ Volpe et al $2009^{39}$} & \multicolumn{3}{|l|}{ Barrios et al 200940 } \\
\hline $\mathbf{N}$ & \multicolumn{3}{|l|}{1,017} & \multicolumn{3}{|l|}{722} \\
\hline BP inclusion criteria & \multicolumn{6}{|c|}{ SeDBP $\geq 100 \mathrm{mmHg}$, SeSBP $\geq 160 \mathrm{mmHg}$, and mean $24-\mathrm{hr}$ DBP $\geq 84 \mathrm{mmHg}$ with $\geq 30 \%$ of daytime DBP $>90 \mathrm{mmHg}$} \\
\hline \multicolumn{7}{|l|}{ Patient characteristics } \\
\hline Mean age, years & \multicolumn{3}{|l|}{55.8} & \multicolumn{3}{|l|}{56.8} \\
\hline Aged $\geq 65$ years $(\%)$ & \multicolumn{3}{|l|}{21.5} & \multicolumn{3}{|l|}{27.0} \\
\hline Caucasian (\%) & \multicolumn{3}{|l|}{99.7} & \multicolumn{3}{|l|}{100} \\
\hline Males (\%) & \multicolumn{3}{|l|}{61.1} & \multicolumn{3}{|l|}{48.9} \\
\hline Diabetes mellitus (\%) & \multicolumn{3}{|l|}{7.2} & \multicolumn{3}{|l|}{8.0} \\
\hline Mean baseline SeBP & \multicolumn{3}{|l|}{$164 / 102 \mathrm{mmHg}$} & \multicolumn{3}{|l|}{$171 / 104 \mathrm{mmHg}$} \\
\hline Open-label monotherapy & \multicolumn{3}{|l|}{ AML 5 mg (8 wks) } & \multicolumn{3}{|l|}{ OM $20 \mathrm{mg}(8 \mathrm{wks})$} \\
\hline \multicolumn{7}{|c|}{ Efficacy of treatment from the end of monotherapy period to end of first 8-week randomized, double-blind phase } \\
\hline $\begin{array}{l}\text { Change in mean BP and } \\
\text { attainment of SeBP goal }\end{array}$ & Treatment (mg/day) & Change (mmHg) & Goal (\%) & Treatment (mg/day) & \multicolumn{2}{|c|}{$\begin{array}{r}\text { Change (mmHg) Goal } \\
(\%)\end{array}$} \\
\hline$<140 / 90 \mathrm{mmHg}$ & AML 5 & $-9.7 /-5.7$ & 30 & OM 20 & $-10.8 /-7.6$ & 28.5 \\
\hline$(<130 / 80 \mathrm{mmHg}$ & AML/OM 5/I0 & $-13.2 /-7.7$ & 39 & AML/OM 5/20 & $-16.1 /-10.4$ & 45.8 \\
\hline \multirow[t]{2}{*}{ for diabetes) } & AML/OM 5/20 & $-15.4 /-9.5$ & 54 & \multirow[t]{2}{*}{ AML/OM I0/20 } & \multirow[t]{2}{*}{$-16.7 /-10.9$} & \multirow[t]{2}{*}{44.5} \\
\hline & AML/OM 5/40 & $-16.8 /-9.6$ & 51 & & & \\
\hline \multicolumn{7}{|c|}{ Efficacy of treatment at end of second 8-week double-blind phase after dose titration } \\
\hline \multirow{5}{*}{$\begin{array}{l}\text { Change in mean BP and } \\
\text { attainment of SeBP goal } \\
<140 / 90 \mathrm{mmHg} \\
\text { ( }<130 / 80 \mathrm{mmHg} \text { for } \\
\text { diabetes) }\end{array}$} & Treatment (mg/day) & Change (mmHg) & Goal (\%) & \multirow[t]{5}{*}{ N/A } & & \\
\hline & AML/OM 5/0 $\rightarrow 5 / 20$ & $-\mid 2.6 /-8.2$ & 38 & & & \\
\hline & AML/OM $5 / 10 \rightarrow 5 / 20$ & $-7.5 /-5.6$ & 28 & & & \\
\hline & AML/OM $5 / 20 \rightarrow 5 / 40$ & $-10.6 /-6.2$ & 36 & & & \\
\hline & AML/OM 5/40 $\rightarrow 10 / 40$ & $-12.3 /-8.2$ & 47 & & & \\
\hline
\end{tabular}

Abbreviations: AML, amlodipine; BP, blood pressure; DBP, diastolic BP, OM, olmesartan medoxomil; SeBP, seated BP; SeDBP, seated DBP; SeSBP, seated SBP.

of the 8-week randomized phase. All treatments significantly reduced SeDBP from baseline in a dose-dependent manner (Table 1). The achievement of BP goal ( $\mathrm{SeBP}<$ 140/90 mmHg; $<130 / 80 \mathrm{mmHg}$ for patients with diabetes) was also assessed. Treatment with amlodipine/olmesartan medoxomil $5 / 20$ or $10 / 20 \mathrm{mg}$ combination therapy led to significantly greater proportions of patients achieving their BP goal, compared with olmesartan medoxomil monotherapy; $P<0.01$ for both combinations vs monotherapy (Table 1). ${ }^{40}$ It is worth noting that the highest United States FDA-approved dosage of olmesartan medoxomil monotherapy ( $40 \mathrm{mg} /$ day) was not used in this European study. ${ }^{24}$

\section{Long-term efficacy of amlodipine/ olmesartan medoxomil}

The long-term efficacy of the amlodipine + olmesartan medoxomil combination was investigated in a 44-week open-label extension (OLE) of the eight-week COACH study. ${ }^{41}$ At the start of the OLE, 1,684 patients were switched to amlodpine/olmesartan medoxomil 5/40 mg. Patients who were not at the SeBP goal $(<140 / 90 \mathrm{mmHg}$; $<130 / 80$ for patients with diabetes) were up-titrated as necessary to amlodipine/olmesartan medoxomil 10/40 $\mathrm{mg}$, followed by the addition of HCTZ 12.5 and $25 \mathrm{mg}$. Back titration and dose adjustment were permitted. Approximately one-quarter of patients $(n=419)$ were up-titrated to amlodipine/olmesartan medoxomil 10/40 $\mathrm{mg}+$ HCTZ $25 \mathrm{mg}$. Mean SeBP changes from baseline (measured at randomization into the 8-week study) ranged from $-30.0 /-19.3 \mathrm{mmHg}$ for amlodipine/olmesartan medoxomil $5 / 40 \mathrm{mg}$ to $-36.1 /-19.8 \mathrm{mmHg}$ for amlodipine/olmesartan medoxomil 10/40 mg + HCTZ $25 \mathrm{mg}$. Overall, $66.7 \%$ of patients in the OLE achieved the SeBP goal. ${ }^{41}$

An extension of the Volpe et $\mathrm{al}^{39}$ study was also conducted. Out of the patients who completed Period III, 692 were enrolled into a 28 -week OLE conducted to assess the effectiveness of long-term treatment with amlodipine/olmesartan medoxomil with or without the addition of HCTZ.42 Patients initially received amlodipine/olmesartan medoxomil 5/40 mg (one patient received $10 / 40 \mathrm{mg}$ ), and most patients $(63 \%)$ remained on this dosage. If SeDBP was $>90 \mathrm{mmHg}$ and SeSBP was $>140 \mathrm{mmHg}$, patients were up-titrated to amlodipine/ olmesartan medoxomil 10/40 mg followed by the addition of HCTZ 12.5 and $25 \mathrm{mg}$ as needed. Of the patients who completed the OLE phase, 436 remained on amlodipine/ 
olmesartan medoxomil 5/40 mg, 142 were up-titrated to amlodipine/olmesartan medoxomil 10/40 mg, and 68 and 27 required the addition of HCTZ $12.5 \mathrm{mg}$ and $25 \mathrm{mg}$, respectively. Up-titration from amlodipine/olmesartan medoxomil 5/40 $\mathrm{mg}$ enabled additional SeBP changes of $-8.8 /-5.5,-10.2 /-6.3$, and $-3.8 /-3.7 \mathrm{mmHg}$ with each titration step. The overall rate of goal achievement (<140/90 mmHg; <130/80 mmHg for patients with diabetes) was $66.9 \%{ }^{42}$

A post hoc analysis of this OLE determined the magnitude of BP reductions observed in patients who received the amlodipine/olmesartan medoxomil 5-10/40 mg combination. ${ }^{43}$ The proportions of patients with categorical SeSBP reductions from baseline of $\leq 15 \mathrm{mmHg},>15$ to $\leq 30 \mathrm{mmHg},>30$ to $\leq 45 \mathrm{mmHg}$, and $>45 \mathrm{mmHg}$ were $12.8 \%, 36.0 \%, 35.3 \%$, and $15.9 \%$, respectively. Unsurprisingly, the greatest SeSBP reductions were associated with the highest rates of achievement of a target of $<140 \mathrm{mmHg}$, with $97.8 \%, 89.7 \%, 77.4 \%$, and $55.4 \%$ from the $>45 \mathrm{mmHg},>30$ to $\leq 45 \mathrm{mmHg},>15$ to $\leq 30 \mathrm{mmHg}$, and $\leq 15 \mathrm{mmHg}$ groups, respectively. ${ }^{43}$

\section{Efficacy of amlodipine and olmesartan medoxomil over the 24-hour dosing interval}

Cardiovascular events appear to occur more frequently in the morning, a phenomenon that has been linked with activation of the sympathetic nervous system that results in hormonal and physiological changes, including an increase in heart rate and $\mathrm{BP}$ elevation. ${ }^{44}$ These morning $\mathrm{BP}$ elevations differ from BP alterations observed with normal changes in position.

Ambulatory BP monitoring (ABPM) is an effective and accurate method of hypertension diagnosis and a valuable tool for optimizing hypertension management. ${ }^{45}$ Ambulatory devices are particularly useful for the detection of white-coat hypertension or masked hypertension and for monitoring patients who are receiving complex antihypertensive treatment protocols. ${ }^{46}$ The use of ABPM also allows the efficacy of antihypertensive medications to be monitored over a 24-hour dosing interval. However, there is a lack of current consensus guidance for ambulatory BP treatment goals.

Two recent studies have indicated that amlodipine/olmesartan medoxomil provides effective BP lowering over a 24-hour period in patients not adequately controlled with amlodipine $5 \mathrm{mg} /$ day monotherapy. ${ }^{47,48}$

\section{4-Hour BP control in patients treated with an amlodipinel olmesartan medoxomil titration regimen}

At the American Society of Hypertension (ASH) 2009 Annual Scientific Meeting, data were presented describing the efficacy of an amlodipine/olmesartan medoxomil-based titration regimen. ${ }^{47}$ Seated BP inclusion criteria were $\mathrm{SeSBP} \geq 140$ and $\leq 199 \mathrm{mmHg}$ and SeDBP $\geq 90$ and $\leq 109 \mathrm{mmHg} .{ }^{49}$ Patients with hypertension received monotherapy with amlodipine $5 \mathrm{mg}$ /day and were up-titrated at 3-week intervals to combination amlodipine/olmesartan medoxomil dosages of 5/20,5/40, and $10 / 40 \mathrm{mg}$ if SeBP was $\geq 120 / 80 \mathrm{mmHg}$. Of the 185 patients who entered the study, $56.8 \%$ were male and the mean age was 56.8 years. Baseline ambulatory BP was $144.8 / 85.7 \mathrm{mmHg}$ for those patients with baseline and end-of-study ABPM readings $(\mathrm{n}=172) .{ }^{47}$ Baseline SeBP for the efficacy cohort $(\mathrm{n}=185)$ was $158.0 / 92.8 \mathrm{mmHg} .{ }^{50}$ The primary efficacy endpoint was the change from baseline in mean 24-hour SBP as assessed by ABPM at Week 12. At Week 12, the titration regimen enabled a change from baseline in mean 24-hour ambulatory BP of $-21.4 /-12.7 \mathrm{mmHg}$, and ambulatory $\mathrm{BP}$ was reduced from baseline throughout the dosing interval including the last 6, 4, and 2 hours. ${ }^{47,51}$ A cumulative SeBP target of $<140 / 90 \mathrm{mmHg}$ was achieved by $76.8 \%$ of patients. ${ }^{50}$

\section{4-Hour BP control in patients receiving amlodipine/olmesartan medoxomil who previously were non-responders to amlodipine monotherapy}

Data recently presented at the ESH 2009 Annual Scientific Meeting showed that reductions in mean 24-hour, daytime, and nighttime ambulatory BP were significantly greater with amlodipine/olmesartan medoxomil combination therapy than with amlodipine monotherapy in patients who had not responded adequately to amlodipine $(P<0.0001$ for each combination dosage vs amlodipine monotherapy). ${ }^{48}$ Furthermore, patients who did not achieve BP goals had further reductions in BP following 8 weeks of dose up-titration. ${ }^{48}$ Changes in mean 24-hour ambulatory BP values from baseline at the end of the double-blind period associated with amlodipine monotherapy were $-3.4 /-2.8 \mathrm{mmHg}$, compared with changes of up to $-10.1 /-7.2 \mathrm{mmHg}$ (for the maximum combination therapy dosage of $5 / 40 \mathrm{mg}$ ). Dose up-titration for a further 8 weeks occurred at the end of the double-blind period in patients who 
were still inadequately controlled (DBP $\geq 90 \mathrm{mmHg}$ and SBP $\geq 140 \mathrm{mmHg}$ ) and provided additional clinically relevant ambulatory BP reductions, eg, further mean 24-hour ambulatory BP changes from baseline of $-8.8 /-6.6 \mathrm{mmHg}$ for patients up-titrated from amlodipine/olmesartan medoxomil 5/40 to $10 / 40 \mathrm{mg} .^{48}$ These data represent a subanalysis of data from the study conducted by Volpe et al. ${ }^{39}$

\section{Safety and tolerability of amlodipine/olmesartan medoxomil}

In large controlled studies, the amlodipine/olmesartan medoxomil combination of 5-10/10-40 mg was generally well tolerated. ${ }^{36,39,40}$ In all studies, the incidences of adverse events were comparable among the different amlodipine/ olmesartan medoxomil dose combinations, the olmesartan medoxomil or amlodipine monotherapy groups, and placebo. ${ }^{36,39,40}$ Overall, most adverse events were of a mild nature and were consistent with the tolerability profile of either CCB or ARB therapy. Across three clinical trials ${ }^{36,39,40}$ in which patients received combination amlodipine/olmesartan medoxomil dosages of 5-10/10-40 mg, commonly occurring drug-related adverse events were headache $(0.0 \%-6.9 \%)$ and dizziness $(0.0 \%-5.0 \%)$; two trials indicated rates of peripheral edema of $0.5 \%$ to $2.3 \%,{ }^{39,40}$ whereas in the third trial $(\mathrm{COACH}),{ }^{36}$ reported rates for edema were between $18.0 \%$ and $26.5 \%$, which is probably due to the fact that this aspect of drug safety was actively assessed in this study.

In 2 trials that compared combination amlodipine/ olmesartan medoxomil therapy with amlodipine monotherapy, the incidence of peripheral edema was lower for combination therapy compared with amlodipine monotherapy when the DHP-CCB dosage was $5^{39}$ or $10 \mathrm{mg} .{ }^{36} \mathrm{In}$ the $\mathrm{COACH}$ trial, among patients receiving amlodipine $10 \mathrm{mg}$, the frequency of edema was $36.8 \%$, but this was reduced to $25.6 \%$ and $23.5 \%$ in patients who received olmesartan medoxomil $20 \mathrm{mg}$ or $40 \mathrm{mg}$, respectively, in combination with amlodipine $(P<0.05$ for both combination dosages vs amlodipine monotherapy). ${ }^{36}$ Similarly, in the Volpe et al study, the lower dosage of amlodipine monotherapy (5 mg/ day) was associated with rates of peripheral edema that were 2- to 4-fold higher than in those who received amlodipine/ olmesartan medoxomil 5/10-40 mg combinations (2.1\% vs $0.5 \%-1.1 \%$; descriptive data only). ${ }^{39}$

In the ABPM study presented at ASH 2009, the most common drug-related adverse events reported in patients were peripheral edema (4/185) and dizziness (2/185), and there were no reports of headache, orthostatic hypotension, or hypotension. ${ }^{47}$

In the OLE of the COACH study, no major safety issues emerged as a consequence of extended therapy. ${ }^{41}$ The incidence of edema continued to be monitored in the OLE and increases in severity were reported as adverse events. Incidences of edema determined to be related to the study drug ranged from $7.0 \%$ to $11.1 \%$ in patients who received amlodipine/olmesartan medoxomil 5/40 and 10/40 mg, respectively. ${ }^{41}$

In the 28-week extension of the Volpe et al study, ${ }^{39}$ drug-related incidences of edema were low in patients who received amlodipine/olmesartan medoxomil 5/40 mg (0.7\%) and $10 / 40 \mathrm{mg}(1.6 \%)$. No edema was reported in patients who were administered HCTZ as a component of the combination regimen. $^{42}$

\section{Patient perspectives}

Fixed-dose combination therapy provides a number of potential advantages, including better adherence, simplified dosing regimens and titration, reduced likelihood of adverse events, lower cost, and improved quality of life. , $^{5,15}$

The simplified dosing schedule associated with combination therapy is linked to improved adherence. Multiple medications and complex treatment regimens lead to poor patient adherence. ${ }^{5}$ In particular, adherence to antihypertensive treatment decreases as dosing frequency increases. ${ }^{52}$ In a Canadian study $(\mathrm{N}=198)$, significantly more patients with hypertension randomized to a once-daily amlodipine regimen took their medication regularly, compared with patients receiving a twicedaily diltiazem regimen. ${ }^{53}$ In another study of patients with diabetes, the average percentage of doses taken decreased by more than $50 \%$ when dosing frequency of an oral antidiabetic agent was increased to 3 times daily from a once-daily regimen (79\% vs 38\%). ${ }^{54}$ These results are supported by findings from 2 more recent studies in patients with hypertension, where observed adherence was greater with fixed-dose combinations than with free combination therapy. ${ }^{55,56}$ It is worth noting that in the earlier study in patients with diabetes, the investigators found that, for the most part, the major nonadherence event was dose omission. ${ }^{54}$ However, more than $33 \%$ of patients took more doses than were prescribed, indicating that decreasing the dose frequency may increase the risk of overmedication. ${ }^{54}$

Because antihypertensive combinations like amlodipine/ olmesartan medoxomil are more effective than single-drug treatment, BP control can be achieved potentially more quickly. ${ }^{57}$ Titration of dose is simplified with fixed-dose combination therapy, which increases convenience for the patient, 5,15 and may therefore increase compliance and adherence. ${ }^{12}$ 
Patients are less likely to experience adverse effects with combination therapy because lower doses of the individual agents can be used. ${ }^{16}$ In addition, one agent can attenuate adverse effects caused by the other agent, ${ }^{5,15}$ for example, as discussed in the tolerability section of this paper, olmesartan medoxomil ameliorates the dose-related peripheral edema that is associated with amlodipine. A further illustration of the adverse effect neutralizing properties of one agent over another is the attenuation of thiazide-induced hypokalemia with concomitant use of ARBs, ACE inhibitors, or potassium-sparing diuretics. ${ }^{5}$

Fixed-dose combination therapy may incur lower overall costs than treatment with the component agents separately because of lower prescription costs and fewer regimen modifications, leading to fewer physician visits. ${ }^{57,58}$ Modifications (not including discontinuations) to drug therapy, regardless of the antihypertensive drug class, have been associated with significantly higher health service costs in the first 12 months of therapy. ${ }^{57}$

In 2 retrospective studies, the annual cost of treatment was significantly lower for patients with hypertension receiving fixed-dose benazepril/amlodipine than for those receiving the free combination. ${ }^{55,56}$ Results from a retrospective database analysis showed that recipients of a once-daily, single-capsule, fixed-dose combination of amlodipine/benazepril required fewer medical resources and that annual per-patient CV-related medical costs were less than those associated with a similar regimen comprised of separate components. ${ }^{55}$ Similarly, in a longitudinal cohort analysis of South Carolina Medicaid claims, fixedcombination antihypertensive therapy was associated with a significant reduction in average total costs of $12.5 \%$, compared with free-combination therapy $(P<0.003) .{ }^{56}$ Furthermore, according to a simulation model, CCB/ARB combination therapy may be more cost effective than monotherapy with either agent alone for lifetime treatment of hypertension in Japan. ${ }^{59}$

Combination antihypertensive therapy may also improve health related quality of life outcomes over monotherapy. A study in patients with poorly controlled hypertension on low-dose amlodipine showed that the combination of amlodipine and the $\beta$-blocker betaxolol significantly improved health-related quality of life, whereas increasing the dose of amlodipine had no significant effect. ${ }^{60}$

\section{Conclusion}

The prevalence of hypertension is increasing worldwide and is a powerful, independent risk factor for CV and renal disease, placing considerable burden on health care resources.
In addition, the majority of patients with hypertension have inadequately controlled BP. It is now recognized that most patients with hypertension will require combination therapy with two or more antihypertensive drugs to achieve BP goals. Extensive evidence shows that a combination of antihypertensive agents with complementary mechanisms of action have a number of additive benefits over monotherapy including a greater BP response and percentage of responders, a reduction in side effects, simplification of dose titration, and improved adherence rates.

The combination of a DHP-CCB (amlodipine) with an ARB (olmesartan medoxomil) is effective in patients with mild-to-severe hypertension, and significantly greater proportions of patients achieve BP goals with this combination treatment compared with the component monotherapies. The efficacies of amlodipine/olmesartan medoxomil combination therapy regimens are maintained over a 24-hour dosing interval. Furthermore, in large clinical trials, amlodipine/olmesartan medoxomil combinations exhibit favorable tolerability profiles. Of note, the incidence of peripheral edema, an adverse event commonly associated with DHP-CCB monotherapy, was significantly less frequent in amlodipine/olmesartan medoxomil combinations compared with high-dose amlodipine monotherapy, where this event was specifically evaluated in a clinical trial.

The combination of amlodipine/olmesartan medoxomil is effective for achieving BP goals in a wide range of patients with hypertension, including patients who have not responded to monotherapy with either agent. The clinical evidence discussed in this review provides a strong rationale for the use of this combination as an antihypertensive treatment strategy, particularly in a single-pill formulation, regardless of patient age, gender, or ethnicity or those with common comorbid conditions such as diabetes.

\section{Acknowledgments}

Editorial support was provided by Stephanie Blick and Christopher J Jones, $\mathrm{PhD}$, of inScience Communications, a part of the Wolters Kluwer organization. Funding for the preparation of the manuscript was provided by Daiichi Sankyo, Inc.

\section{Disclosures}

Jan Basile, MD, receives grant/research support from the NHLBI and Novartis, serves as a consultant for Abbott Laboratories, Daiichi Sankyo, Inc., GlaxoSmithKline, Novartis, and Takeda Pharmaceuticals, and is on the Speakers' Bureau for Abbott Laboratories, AstraZeneca, Daiichi Sankyo, Inc., Forest Laboratories, GlaxoSmithKline, and Novartis. 


\section{References}

1. Ong KL, Cheung BM, Man YB, Lau CP, Lam KS. Prevalence, awareness, treatment, and control of hypertension among United States adults 1999-2004. Hypertension. 2007;49(1):69-75.

2. Hajjar I, Kotchen TA. Trends in prevalence, awareness, treatment, and control of hypertension in the United States, 1988-2000. JAMA. 2003;290(2):199-206.

3. Lloyd-Jones D, Adams R, Carnethon M, et al. Heart disease and stroke statistics-2009 update: a report from the American Heart Association Statistics Committee and Stroke Statistics Subcommittee. Circulation. 2009;119(3):e21-e181.

4. Rosendorff C, Black HR, Cannon CP, et al. Treatment of hypertension in the prevention and management of ischemic heart disease: a scientific statement from the American Heart Association Council for High Blood Pressure Research and the Councils on Clinical Cardiology and Epidemiology and Prevention. Circulation. 2007;115(21):2761-2788.

5. Pimenta E, Oparil S. Fixed combinations in the management of hypertension: patient perspectives and rationale for development and utility of the olmesartan-amlodipine combination. Vasc Health Risk Manag. 2008;4(3):653-664.

6. Kearney PM, Whelton M, Reynolds K, Muntner P, Whelton PK, He J. Global burden of hypertension: analysis of worldwide data. Lancet. 2005;365(9455):217-223.

7. Lawes CM, Vander Hoorn S, Rodgers A. Global burden of bloodpressure-related disease, 2001. Lancet. 2008;371(9623):1513-1518.

8. Mancia G, De Backer G, Dominiczak A, et al. 2007 guidelines for the management of arterial hypertension: the task force for the management of arterial hypertension of the European Society of Hypertension (ESH) and of the European Society of Cardiology (ESC). J Hypertens. 2007;25(6):1105-1187.

9. Chobanian AV, Bakris GL, Black HR, et al. The seventh report of the Joint National Committee on prevention, detection, evaluation, and treatment of high blood pressure: the JNC 7 report. JAMA. 2003;289(19):2560-2572.

10. Mancia G, Laurent S, Agabiti-Rosei E, et al. Reappraisal of European guidelines on hypertension management: a European Society of Hypertension Task Force document. J Hypertens. 2009; Oct 15. [E-pub ahead of print].

11. Appel LJ, Giles TD, Black HR, et al. ASH position paper: dietary approaches to lower blood pressure. JClin Hypertens (Greenwich). 2009; 11(7):358-368.

12. Moser M. Rationale for combination therapy in the management of hypertension. J Clin Hypertens (Greenwich). 2003;56 Suppl 4:17-25.

13. Calhoun DA, Lacourciere Y, Chiang YT, Glazer RD. Triple antihypertensive therapy with amlodipine, valsartan, and hydrochlorothiazide: a randomized clinical trial. Hypertension. 2009;54(1):32-39.

14. Novartis Pharmaceuticals Corporation. Novartis receives FDA approval for Valturna ${ }^{\circledR}$, a single-pill combination of valsartan and aliskiren, to treat high blood pressure. 2009 Sep 17. Available from: http://www. pharma.us.novartis.com/newsroom/press-release.jsp?PRID=2261 Accessed Apr 24, 2010.

15. Oparil S, Weber M. Angiotensin receptor blocker and dihydropyridine calcium channel blocker combinations: an emerging strategy in hypertension therapy. Postgrad Med. 2009;121(2):25-39.

16. Law MR, Wald NJ, Morris JK, Jordan RE. Value of low dose combination treatment with blood pressure lowering drugs: analysis of 354 randomised trials. BMJ. 2003;326(7404):1427.

17. Turnbull F. Effects of different blood-pressure-lowering regimens on major cardiovascular events: results of prospectivelydesigned overviews of randomised trials. Lancet. 2003;362(9395): $1527-1535$.

18. Yusuf S, Teo KK, Pogue J, et al. Telmisartan, ramipril, or both in patients at high risk for vascular events. $N$ Engl J Med. 2008; 358(15):1547-1559.

19. Costanzo P, Perrone-Filardi P, Petretta M, et al. Calcium channel blockers and cardiovascular outcomes: a meta-analysis of 175,634 patients. $J$ Hypertens. 2009;27(6):1136-1151.
20. Dahlof B, Sever PS, Poulter NR, et al. Prevention of cardiovascular events with an antihypertensive regimen of amlodipine adding perindopril as required versus atenolol adding bendroflumethiazide as required, in the Anglo-Scandinavian Cardiac Outcomes Trial-Blood Pressure Lowering Arm (ASCOT-BPLA): a multicentre randomised controlled trial. Lancet. 2005;366(9489):895-906.

21. Nissen SE, Tuzcu EM, Libby P, et al. Effect of antihypertensive agents on cardiovascular events in patients with coronary disease and normal blood pressure: the CAMELOT study: a randomized controlled trial. JAMA. 2004;292(18):2217-2225.

22. Jamerson K, Weber MA, Bakris GL, et al. Benazepril plus amlodipine or hydrochlorothiazide for hypertension in high-risk patients. $N \mathrm{Engl}$ J Med. 2008;359(23):2417-2428.

23. Dahlof B, Devereux RB, Kjeldsen SE, et al. Cardiovascular morbidity and mortality in the Losartan Intervention For Endpoint reduction in hypertension study (LIFE): a randomised trial against atenolol. Lancet. 2002;359(9311):995-1003.

24. Daiichi Sankyo, Inc. AZOR (amlodipine and olmesartan medoxomil tablets) Prescribing Information. 2009. Available from: http://www. azor.com/hcp/utilities/prescribing_information.html. Accessed Apr 24, 2010.

25. Prisant LM. Calcium antagonists. In: Oparil S, Weber M, editors. Hypertension: A Companion to Brenner and Rector's the Kidney. 2nd ed. Philadelphia: Elsevier; 2005:683-704

26. Meredith PA, Elliott HL. Clinical pharmacokinetics of amlodipine. Clin Pharmacokinet. 1992;22(1):22-31.

27. Schwocho LR, Masonson HN. Pharmacokinetics of CS-866, a new angiotensin II receptor blocker, in healthy subjects. J Clin Pharmacol. 2001;41(5):515-527.

28. Rohatagi S, Lee J, Shenouda M, et al. Pharmacokinetics of amlodipine and olmesartan after administration of amlodipine besylate and olmesartan medoxomil in separate dosage forms and as a fixed-dose combination. J Clin Pharmacol. 2008;48(11):1309-1322.

29. Bolbrinker J, Huber M, Scholze J, Kreutz R. Pharmacokinetics and safety of olmesartan medoxomil in combination with either amlodipine or atenolol compared to respective monotherapies in healthy subjects. Fundam Clin Pharmacol. 2009;23(6):767-774.

30. Goodfriend TL. Angiotensins: actions and receptors. In: Izzo JL Jr, Black HR, Goodfriend TL, editors. Hypertension Primer: The Essentials of High Blood Pressure. 3rd ed. Philadelphia: Lippincott, Williams \& Wilkins; 2003:8-11.

31. Mire DE, Silfani TN, Pugsley MK. A review of the structural and functional features of olmesartan medoxomil, an angiotensin receptor blocker. J Cardiovasc Pharmacol. 2005;46(5):585-593.

32. Weber MA. Angiotensin II receptor blockers. In: Izzo JL, Jr, Black HR, editors. Hypertension Primer, The Essentials of High Blood Pressure. Philadelphia: Lippincott, Williams \& Wilkins; 2003;430-432.

33. Kakuta H, Sudoh K, Sasamata M, Yamagishi S. Telmisartan has the strongest binding affinity to angiotensin II type 1 receptor: comparison with other angiotensin II type 1 receptor blockers. Int J Clin Pharmacol Res. 2005;25(1):41-46.

34. Carey RM, Wang ZQ, Siragy HM. Role of the angiotensin type 2 receptor in the regulation of blood pressure and renal function. Hypertension. 2000;35(1 Pt 2):155-163.

35. Krum H. Critical assessment of calcium antagonists. Aust Fam Physician. 1997;26(7):841-845.

36. Chrysant S, Melino M, Karki S, Lee J, Heyrman R. The combination of olmesartan medoxomil and amlodipine besylate in controlling high blood pressure: $\mathrm{COACH}$, a randomized, double-blind, placebocontrolled, 8-week factorial efficacy and safety study. Clin Ther. 2008;30(4):587-604.

37. Oparil S, Lee J, Karki S, Melino M. Subgroup analyses of an efficacy and safety study of concomitant administration of amlodipine besylate and olmesartan medoxomil: evaluation by baseline hypertension stage and prior antihypertensive medication use. J Cardiovasc Pharmacol. $2009 ; 54: 427-436$ 
38. Chrysant SG, Lee J, Melino M, Karki S, Heyrman R. Efficacy and tolerability of amlodipine plus olmesartan medoxomil in patients with difficult-to-treat hypertension. J Hum Hypertens. 2010 Feb 18. [E-pub ahead of print].

39. Volpe M, Brommer P, Haag U, Miele C. Efficacy and tolerability of olmesartan medoxomil combined with amlodipine in patients with moderate to severe hypertension after amlodipine monotherapy: a randomized, double-blind, parallel-group, multicentre study. Clin Drug Investig. 2009;29(1):11-25.

40. Barrios V, Brommer P, Haag U, Calderon A, Escobar C. Olmesartan medoxomil plus amlodipine increases efficacy in patients with moderate-to-severe hypertension after monotherapy: a randomized, doubleblind, parallel-group, multicentre Study. Clin Drug Investig. 2009; 29(7):427-439.

41. Chrysant SG, Oparil S, Melino M, Karki S, Lee J, Heyrman R. Efficacy and safety of long-term treatment with the combination of amlodipine besylate and olmesartan medoxomil in patients with hypertension. $J$ Clin Hypertens (Greenwich). 2009;11(9):475-482.

42. Volpe M, Miele C, Haag U. Efficacy and safety of a stepped-care regimen using olmesartan medoxomil, amlodipine and hydrochlorothiazide in patients with moderate-to-severe hypertension: an open-label, long-term study. Clin Drug Investig. 2009;29(6):381-391.

43. Mourad JJ, Le Jeune S. Effective systolic blood pressure reduction with olmesartan medoxomil/amlodipine combination therapy: post hoc analysis of data from a randomized, double-blind, parallel-group, multicentre study. Clin Drug Investig. 2009;29(6):419-425.

44. Gosse P, Lasserre R, Minifie C, Lemetayer P, Clementy J. Blood pressure surge on rising. J Hypertens. 2004;22(6):1113-1118.

45. Chavanu K, Merkel J, Quan AM. Role of ambulatory blood pressure monitoring in the management of hypertension. Am J Health Syst Pharm. 2008;65(3):209-218.

46. Pickering TG, White WB. ASH position paper: home and ambulatory blood pressure monitoring. When and how to use self (home) and ambulatory blood pressure monitoring. J Clin Hypertens (Greenwich). 2008;10(11):850-855.

47. Neutel JM, Kereiakes DJ, Punzi H, et al. Efficacy and safety of an amlodipine/olmesartan medoxomil-based titration regimen on blood pressure (BP) assessed by mean 24-hr ambulatory BP monitoring in patients with hypertension J Clin Hypertens. 2009;11 Suppl 4:A129.

48. Heagerty AM, Laeis P, Haag U. Olmesartan medoxomil/amlodipine (OLM/AML) provides 24-hour antihypertensive efficacy - additional effect by uptitration in patients with moderate-to-severe hypertension. J Hypertens. 2009;27 Suppl 4:S283.

49. Daiichi Sankyo, Inc, ClinicalTrials.gov. Blood Pressure Lowering Ability and Safety of an Olmesartan and Amlodipine Based Treatment Regimen in Patients With Stage I and Stage II Hypertension. 2009 Nov 4. Available from: http://clinicaltrials.gov/ct2/show/NCT00527514 Accessed Apr 24, 2010.
50. Punzi H, Lewin A, Shojaee A, Waverczak WF, Dubiel R, Xu J. Efficacy of an amlodipine/olmesartan medoxomil-based titration regimen on blood pressure goal achievement in patients with hypertension $J$ Clin Hypertens. 2009;11 Suppl 4:A133.

51. Neutel JM, Littlejohn III T, Shojaee A, Waverczak WF, Dubiel R, Xu J. 24 hour efficacy of an amlodipine/olmesartan medoxomil-based titration regimen on blood pressure at daytime, nighttime and last 6, 4, 2 hours of dosing interval. J Clin Hypertens. 2009;11 Suppl 4:A130.

52. Sica DA. Fixed-dose combination antihypertensive drugs. Do they have a role in rational therapy? Drugs. 1994;48(1):16-24.

53. Leenen FH, Wilson TW, Bolli P, et al. Patterns of compliance with once versus twice daily antihypertensive drug therapy in primary care: a randomized clinical trial using electronic monitoring. Can J Cardiol. 1997;13(10):914-920.

54. Paes AH, Bakker A, Soe-Agnie CJ. Impact of dosage frequency on patient compliance. Diabetes Care. 1997;20(10):1512-1517.

55. Taylor AA, Shoheiber O. Adherence to antihypertensive therapy with fixed-dose amlodipine besylate/benazepril $\mathrm{HCl}$ versus comparable component-based therapy. Congest Heart Fail. 2003;9(6):324-332.

56. Dickson M, Plauschinat CA. Compliance with antihypertensive therapy in the elderly: a comparison of fixed-dose combination amlodipine/ benazepril versus component-based free-combination therapy. Am J Cardiovasc Drugs. 2008;8(1):45-50.

57. Saleh SS, Szebenyi S, Carter JA, Zacher C, Belletti D. Patterns and associated health services costs of antihypertensive drug modifications. J Clin Hypertens (Greenwich). 2008;10(1):43-50.

58. Rabbani A, Alexander GC. Out-of-pocket and total costs of fixed-dose combination antihypertensives and their components. Am J Hypertens. 2008;21(5):509-513.

59. Saito I, Kobayashi M, Matsushita Y, Mori A, Kawasugi K, Saruta T. Cost-utility analysis of antihypertensive combination therapy in Japan by a Monte Carlo simulation model. Hypertens Res. 2008; 31(7):1373-1383.

60. Takase B, Takeishi Y, Hirai T, et al. Comparative effects of amlodipine monotherapy and combination therapy with betaxolol on cardiac autonomic nervous activity and health-related quality of life in patients with poorly controlled hypertension. Circ J. 2008;72(5):764-769.

61. Neutel JM. Complementary mechanisms of angiotensin receptor blockers and calcium channel blockers in managing hypertension. Postgrad Med. 2009;121(2):40-48.
Integrated Blood Pressure Control

\section{Publish your work in this journal}

Integrated Blood Pressure Control is an international, peer-reviewed open-access journal focusing on the integrated approach to managing hypertension and risk reduction. Treating the patient and comorbidities together with diet and lifestyle modification and optimizing healthcare resources through a multidisciplinary team approach constitute key

\section{Dovepress}

features of the journal. This journal is indexed on American Chemical Society's Chemical Abstracts Service (CAS). The manuscript management system is completely online and includes a very quick and fair peerreview system, which is all easy to use. Visit http://www.dovepress.com/ testimonials.php to read real quotes from published authors 